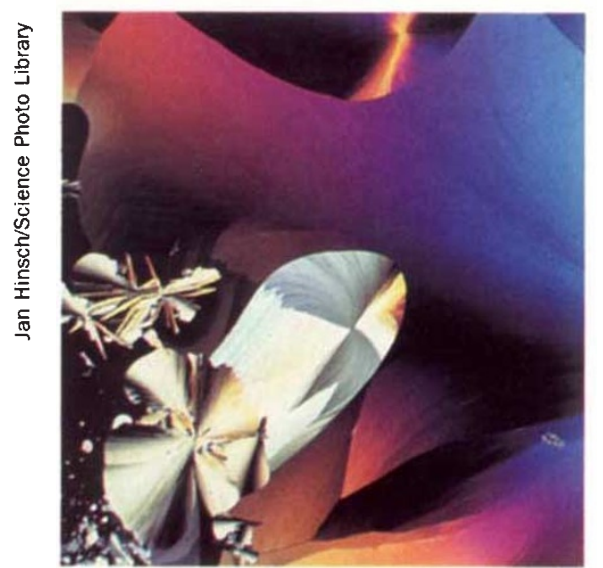

Polarized light micrograph of crystals of phloroglucin $(\times 14)$.

the articles published in 1990 , which are of consistently good quality. Most of the papers combine experimental and theoretical studies and cover a wide range of organic and inorganic systems. Popular topics include molecular mechanics and quantum mechanics calculations as well as single-crystal and electrondiffraction structure determinations. The articles are well presented, and the journal is a pleasure to read. It looks like becoming a high-quality journal in an important and expanding field.

But what about the competition? There are already several journals that cater for the structural chemist but these are mainly restricted to one topic or another. Few encourage the breadth of topics that are covered in Structural Chemistry, where the juxtaposition of articles about different areas is a particularly pleasing aspect.

Recent advances in computer technology and development of theoretical techniques now enable us to investigate interesting molecules of a fairly large size. Results from these studies need to be compared with experimental work, and for that reason alone, this new journal is to be welcomed.

Is the journal necessary? Certainly the articles here could be usefully published in several other journals. But as published scientific material expands every year, new journals are necessary and this one has found a suitable gap in the market-place.

The stated aim of Structural Chemistry is to overcome the unnatural separation that exists in the current literature among the sciences of structure determination, energetics and applications, and to build a bridge to other chemical disciplines.

The journal has made a considerable impression in its first year of publication and I recommend it to all structural chemists.

Michael G. B Drew is in the Department of Chemistry, University of Reading, Reading RG6 2AD, UK.

\section{Tying together}

\section{R. A. Pethrick}

Polymers for Advanced Technologies. Editor-in-chief Menachem Lewin. Wiley. $8 / y r . \$ 450$ (institutional); $\$ 340,1185$ (personal).

POLYMERIC materials are finding increasing use in the development of new materials for advanced technologies. This journal attempts to provide a focus for research in this area, and deals with organic, inorganic, multiphase and composite polymers with application in electronics, information science, aerospacerelated industries, automotive industries, packaging, imaging, integrated circuit manufacture, agriculture and pharmaceutical industries. The topics covered are divided into four subheadings: radiation-related polymers, advanced structures, polymers for biosystems and materials. The journal provides a suitable focus for papers that are currently finding an uneasy home in more conventional single-discipline journals, and addresses the multidisciplinary nature of much of the work in this area. The first volume covers topics spanning poly-

\section{Solid start}

\section{Paul Calvert}

Journal of Materials Chemistry. Editor A. R. West. Royal Society of Chemistry. 12/yr. European Communities £280, US $\$ 599$, Canada $\$ 331$, elsewhere 1315 (institutional).

OVER the past few years materials have become recognized as a key technology for industrial growth. This has been expressed by the growing funding for materials science with promises, in the United States, of larger increases to come over the next year or so. The result of this public attention has also been that solid-state physicists, and inorganic and solid-state chemists, have realized that they are really materials scientists too. The true materials community is becoming nervous about being crushed in the stampede by these large herds. Both the American Chemical Society and the Royal Society of Chemistry have produced journals to reflect this materials involvement among chemists. The American Chemical Society journal Chemistry of Materials is now in its third year. Journal of Materials Chemistry was started this year by the Royal Society of Chemistry.

This participation by chemists also reflects a shift in emphasis in materials electrolytes, liquid-crystalline polymers, electro-optic properties, photocrosslinking systems, resists and piezoelectricity.

The A4 format of the journal is clear and easy to read, but the reason for the second issue being smaller in size is not clear. The inclusion of a key-word index is valuable considering that many of the papers are of a multidisciplinary nature. One of the papers in the first volume contained eight pages of theoretical calculations on heat capacities, information which was also presented in graphical form and in terms of the component equations. Duplication of information of this sort is rather expensive and should be avoided; perhaps the policy adopted by other journals of providing supplementary information on request would be a useful ploy here, and would reduce such large amounts of tabular material. The reproduction of electron micrographs in two of the papers was very poor, causing information to be lost for the reader.

Despite these criticisms the journal makes a good overall impression and is likely to fill a gap for those involved in the development of new materials for advanced technologies.

R. A. Pethrick is in the Department of Pure and Applied Chemistry, University of Strathclyde, Glasgow G1 $1 X L$, UK.

science. The traditional heartland of materials science is the exploration of the effect of changes in microstructure on properties. Thus strength in metals or ceramics is affected by annealing treatments or alloying additions, which modify grain size. The starting metal, ceramic powder or polymer, was usually supplied by industry.

Nowadays there is far more emphasis on new materials such as the hightemperature superconductors, nonlinear optical polymers and precursor polymers for ceramics. Physicists are needed to predict what molecular structures will have the desired properties and chemists are needed to make these structures. The real materials science starts when we have identified a high-temperature superconductor and want to turn it into a wire with usable strength and currentcarrying capacity.

These two new 'chemistry and materials' journals serve this field of synthesis of solids, as opposed to the more usual synthetic goal of making soluble compounds with new types of bonding. In his introductory editorial to Journal of Materials Chemistry, Anthony West describes its area as synthesis or fabrication, structure determination and property measurement of both organic and inorganic materials. Many of the materials papers from chemistry departments do emphasize synthesis coupled 